\title{
LA ERECCIÓN DE LOS OBISPADOS DE CUENCA Y SEPÚLVEDA EN EL CONTEXTO DE LA REPOBLACIÓN FORAL
}

\author{
Antonio Linage Conde
}

Al maestro perenne don Claudio Sánchez-Albornoz, en el recuerdo de sus postreras evocaciones en el viejo Ministerio de la Guerra, la casa frontera de la de su nacimiento en la calle de Prim.

El Fuero de Cuenca es un cuerpo legal mandado redactar y concedido por Alfonso VIII el año 1177.

El Fuero de Sepúlveda es una recopilación de derecho consuetudinario aprobada por el Concejo de Sepúlveda el año 1300 (1), aunque el dicho concejo la atribuía a Alfonso VI y la databa en 1076. Pero de Alfonso VI era únicamente una parte mínima que fue escrita en latín y en esa redacción original (2) se conserva parte, si bien remontaba en versiones que se han perdido al conde Fernán González y a sus sucesores intermedios entre él y Alfonso VI en la soberanía del territorio castellano.

De la relación entre los dos fueros, el de Sepúlveda y el de Cuenca, se ha escrito bastante, aunque no con mucha variedad, de manera que las opiniones pueden reducirse a dos: la de Rafael de Ureña (3), de ser el código sepulvedano un cierto plagio del conquense; y la de Rafael Gibert (4), de ser el conquense, por el contrario, una puesta por escrito del consuetudinario sepulvedano, aunque a su vez se sirvieran de él luego en Sepúlveda para la correspondiente redacción escrita de su tal derecho.

Sepúlveda fue repoblada por Fernán González el año 941 (5). 
Cuenca fue reconquistada por Alfonso VIII el año 1177.

La diócesis de Sepúlveda tuvo una existencia jurídico-canónica efímera, de 1107 a 1119-1124, y no llegó a contar con obispo propio sino que fue gobernada por el de Toledo.

La de Cuenca fue erigida el año 1177 o el 1182 y su duración ha sido ininterrumpida hasta nuestros dias.

Así las cosas, puede parecer una divagación ensayística e incluso meramente fantasiosa esta nuestra tentativa de relacionar ambas situaciones históricas, tan distanciadas en la cronología como en los resultados.

Es más. No vamos a negar que algo tenga de lo uno y de lo otro.

Y sin embargo creemos que no será baldia para ayudar al entendimiento de ese entrecruzarse de los dos procesos, el de la reconquista y el de la repoblación, que han sido los forjadores de España, a cuya comprensión el revisionismo integral y dogmático de las posturas tradicionales, por su parte carentes de acervo de la aportación erudita posterior y encastilladas en una óptica que creía poder bastarse a sí misma, no ha contribuido siempre felizmente.

\section{UN BALANCE MUY DIVERSO}

En 1629 publicaba su Historia de la muy noble y leal ciudad de Cuenca, Juan-Pablo Mártir Rizo.

Y dentro de su erudición copiosa, explayada en una prosa sencilla, nada proclive a los desbordamientos barrocos de la época aunque la cobijara el frontispicio sostenido por ondulantes columnas ornadas de hojarescas y estrías enmarcadoras de las imágenes mitradas de San Honorato y San Julián, podía cantar al obispo de Cuenca como una vieja realidad pero con vigencia próspera y fecunda en sus mismos días.

De una «riqueza» poseedora de "gran nombre entre todas las iglesias de España, de suerte que paga más subsidio y excusado que ninguno de los obispados de Castilla y León y más que los arzobispados de Santiago y Granada; sóla la exceden Toledo, Sevilla y Burgos», sirviéndose «con trece dignidades, vientiseis canonicatos, vientidos raciones -doce enteras y doce medias-, veinticuatro capellanes, doce infantes de coro, cuatro salmistas y dos sochantres, los cuales asisten al servicio del coro todos los días, sin otro número de cantores $v$ menestriles que son muchos» y tenièndo bajo su dependencia «354 
pilas, 900 ermitas, 8 arciprestazgos, 20 vicarías, 255 curatos, 130 beneficios simples, 103 préstamos, 307 prestameras, 702 capellanias, una iglesia colegial en Belmonte, 61 conventos de religiosos y monjas, 2800 clérigos", a lo largo de sus treinta y dos leguas de longitud y veintinueve de anchura "donde hay dos ciudades, Cuenca y Huete, 114 villas, 255 aldeas, que en todas hacen 369 lugares», corriendo el Duero por el «brazo que va al septentrión, del brazo meridional del Tajo, distante una legua más bajo el Júcar, media legua más abajo el Guadalobiar, y teniendo principio en la misma sierra más abajo el Jalón que en Aragón se mezcla con el Ebro», con lo cual, de Valencia a Portugal — mare nostrum a mar tenebroso - y tocando el dicho Aragón y las dos Castillas, compendia y encierra la encrucijada de las vertientes y de las cumbres de todas las Españas.

Hasta el extremo de que, siendo tanto el haber de Cuenca en el pasado y el presente, y en su paisaje y paisanaje, se ha podido escribir sin hipérbole que su diócesis es lo que más a su nombre llena.

Diócesis cuya acta de nacimiento está escrita en el mismo folio de la historia que su reconquista y puede reivindicar al monarca protagonista de ésta también por su creador. No sabemos si llevado o no de las elevadas disquisiciones posteriores del mismo Mártir Rizo, de que «cuando Aristóteles propone las cosas, que sin ellas no puede fundarse una república, dice: lo quinti y principal de todo es el cuidado del servicio de Dios que llamamos culto divino», y «por esto el rey don Alonso luego que la ganó de los moros fundó su iglesia catedral, poniendo la primera piedra de aquel edificio».

Muy otro había de ser a la postre, aunque ab initio algo de común tuviera con éste, el caso sepulvedano.

Y por eso creemos que su cotejo no es baldío para comprender hasta donde llega lo uno y desde donde comienza lo vario dentro de esa conjunción doble repobladora de lo reconquistado, si se nos permite simplificar un tanto (6).

\section{EL TEATRO HISTÓRICO SEPULVEDANO}

Deciamos que la repoblación de Sepúlveda se data el año 941 y que el autor de la misma, el conde Fernán González, fue también quien la concedió su fuero, aunque éste no se nos haya conservado, sino sólamente su confirmación por Alfonso $\mathrm{VI}$ el año 1076. Ahora bien, ¿se trata nada más que de una laguna en la tradición textual?. Desde luego que no. Porque, sin adelan- 
tarnos en la cuestión de si la versión alfonsina puede o no coincidir del todo con la fernandina perdida (7), lo cierto es que Alfonso $V \mid$ fue quien consumó la repoblación de la villa, y no únicamente su ordenamiento jurídico.

Y es que la repoblación de Fernán Gonzaléz debió ser de mínima entidad, parece que bastante exclusivamente militar por ello. $Y$ sobre todo que no pudo desarrolarse con arreglo al proceso natural de las cosas porque la villa cambió de manos, siendo víctima de campañas exitosas musulmanas después y parece que habiendo de ser recuperada a la postre por la fuerza de las armas del conde Sancho García, nieto de Fernán (8). Por cierto que de esa manera botón de muestra también de ese entrecruzamiento que acabamos de decir de los procesos decisorios y mutuamente condicionados en la forja hispana, repoblación y reconquista (9), y ello dejando de lado las conexiones reconquistadoras de la misma repoblación sepulvedana -notemos su vecindad cronológica con la batalla de Simancas y lo que geográficamente supone de avanzada hacia el sur con la amenaza consiguiente a lo que ya no era desierto estratégico o tierra de nadie.

Así las cosas, Alfonso VI hubo de encontrársela en acusada precariedad demográfica. Un detalle que lo abona es que entre los confirmantes que le precedieron en la confirmación del fuero fernandino está su abuelo Sancho el Mayor pero no su padre Fernando I. Y el caso era que los designios de aquél sobre la incorporación de Toledo a sus estados, que conseguiría el año 1085 , necesitaban de la villa como una pieza clave en el camino de Burgos a la antigua capital visigoda. Bástenos con notar su posición geográfica en relación con el paso de Somosierra (10). Agudamente lo ha visto uno de los más sólidos investigadores de nuestro medievo, a quien hay que rendir este merecido tributo por haber sabido penetrar todos los aspectos de la historia aun partiendo de una óptica y especialidad economicistas, Jean GautierDalché, el cual escribe (11): «La vocación de Sepúlveda, es pues, militar ante todo, y ese es el sentido inmediato de su restauración. Es un puesto avanzado (12) del reino de Castilla, que podía llegar a ser una base si había que decidirse a pasar de la dominación económica de la taifa toledana a su conquista».

Una vocación militar, sí. Pero que no era contingencia del momento. Sino que remontaba nada menos que al nacimiento de la población, que fue la razón de éste, por ser el paso del río Duratón alli encañonado (13) y confluente con el arroyo Caslilla, y en la etapa anterior a la romanización línea divisoria entre vacceos y arevacos. Tal y como lo ha podido ver un arqueólogo, buen conocedor del país, a pesar de la falta de su exploración arqueológica, Antonio Molinero Pérez, recientemente desaparecido y a quien también 
es justo recordar aqui por la equivalente solidez de sus poco ruidosas aportaciones: «El emplazamiento de Sepúlveda en la confluencia del Duratón y el Caslilla, y la configuración del cerro en que se asienta (14), estupenda para la defensa, permitía asegurar la existencia allí de un castro céltico a priori (15) [aunque no se hubieran hallado las armas y cerámicas que lo abonan (16). Castros que se construían en sitios cuyo emplazamiento prporcionaba de por sí una destacada defensa natural, evitando en lo posible la realización de obras artificiales para la construcción de murallas que en todo caso servirían de complemento o refuerzo de aquellas, como en la confluencia de los ríos que cavaron profundos barrancos]».

Y ¿no nos ha saltado ya a la vista un cierto paralelo topográfico con Cuenca?

\section{LA DIÓCESIS DE SEPÚLVEDA. 1107-1122}

El 8 de mayo de 1107 Alfonso VI se encuentra en el castillo de Monzón, al frente de su ejército, camino de Aragón, el Aragón del nuevo rey Alfonso I, ya batallador, y de vuelta de León, donde había presidido un concilio, eclesiástico naturalmente, que dirimió cuestiones de límites entre las mitras de Compostela y Mondoñedo.

¿Dónde vas, Alfonso VI?, le ha preguntado a este otro cabo de la noche de los tiempos don Claudio Sánchez-Albornoz (18), conformándose a la fuerza con apuntar algunas interrogantes más del inquietante viaje (19), que por otra parte duda incluso si el soberano llegó a consumar o no. Roborata (20) vero in castro de Monzon, coram omni sue expeditionis multitudine, dum iter tenderet ad Aragon, post celebratum concilium apud Legionem, que termina la escritura imperante que va a ser nuestro argumento.

Una escritura en la cual se dona la diócesis de Sepúlveda al arzobispo de Toledo, mencionándose expresamente al titular de éste, don Bernardo. La diócesis de Sepúlveda, una diócesis (21) que así queda erigida naturalmente en cuanto del monarca dependía y a la espera de la presunta venia pontificia - aunque su ordinario fuera, al menos de momento, el mismo de la sede primada. Inicialmente don Bernardo, desde entonces arzobispo de Toledo y administrador apostólico de Sepúlveda. De omni diocesi de Seppulveca (sic). Cualidad de diócesis que machaconamente reitera dos veces más, omnem supra scriptum diocesim y tota diocesis illa. Y que delimita de una doble manera, una concreta y estrictamente geográfica - por lós cuatro puntos cardinales-, a saber todo el territorio comprendido entre el río Duero 
y la Cordillera Central y las diócesis de Avila y Osma, luego de precisarla más bien toponímicamente, cum toto campo de Spina et Segobia. Las tales fronteras no pueden estar más claras: a flumine Durio usque ad montes et a termino Avilensis usque ad terminum Auxumensem, y a pesar de ello las repite, sicut dividitur per terminos Auxumensis sedis et Avilensis, de cacumine montium utriusque terminis usque ad flumen Durium. $Y$ otra, mediante una apelación a la historia, pues se trata de una herencia de la extinta diócesis visigoda de Segovia, todavía en proceso de repoblación (22), et sicut in antiquis divisionibus vel testamentis catholicorum regum invenire potueritis vel perquirere pristinam diffinitionem aut pro debito Segobiensis ecclesie vendicare.

El rey hace constar expresamente, como si necesitara justificar ese acto de soberanía, su repoblación del territorio en cuestión, un país antes patrimonio exclusivo de los osos, los jabalíes y toda clase de fieras y ahora habitado por labradores $y$ defendido por varias e inexpugnables fortalezas.

$Y$ de esta manera creemos que los textos cantan (23). Cantan la erección de la diócesis de Sepúlveda. La restauración de la diócesis de Segovia en Sepúlveda, en todo caso. No la restauración de la diócesis de Segovia como se ha pretendido (24).

Pero claro está, ya lo decíamos, se trata de una erección unilateral por el rey. ¿Cuál fue la respuesta del papa?.

Desde luego que sorprendente. Pues lo que hace Pascual II (25), por su bula del 17 de marzo de 1112 es restaurar, ahora ya es innegable, la diócesis de Segovia. En unos términos que varian totalmente de sentido según sea licet o nisi la palabra que en las distintas versiones del documento figure. De ser la primera se restaura, pero sigue encomendada a la posesión y jurisdicción de la mitra de Toledo, siempre como una especie de administración apostólica, o sea tal y como antes había hecho el rey con la de Sepúlveda, exactamente lo mismo. De preferirse la segunda, se restaura desde un principio con obispo propio, y en consecuencia se priva de su territorio a la dicha sede primada, si es que la capitalidad, Segovia, se empeñaba en ello (25). Secoviensem civitatem, [licet o nisi] proprium desideret civitas ipsa episcopum, persone tue pro gravioris paupertatis necessitate permittimus.

La alternativa desde luego que denota de por sí una fuerte tensión entre Toledo y Segovia. Tanto que «no nos cabe duda de lo indubitado» del deseo segoviano de ser cabeza de obispado.

Pero esto, con ser trascendente para otros aspectos de la historia, a nuestros propósitos no cuentan demasiado, por lo cual no tenemos huelgo para tratar de ello aquí. 
Pues lo que nos interesa es la situación de la nueva diócesis de Sepúlveda a la también nueva luz de la intervención romana. Porque la bula papal no la confirma pero tampoco la extingue. Por lo cual habría habido motivos para darla por subsistente, en potencia al menos, y dejando la problemática así planteada cual un asunto de límites territoriales entre ambas recién nacidas diócesis a dirimir después. Habría habido para ello motivo aunque no contáramos con otros argumentos concretos. Mas se da el caso de que sí los tenemos. Y es que don Bernardo, el mismo arzobispo toledano destinatario el año 1107 de la liberalidad alfonsina a su sede, cedió después Sepúlveda a la ya restaurada Segovia, probablemente a principios de 1122, como nos consta por la confirmación que de su escritura haría después su sucesor don Raimundo en el concilio de Carrión de 1130 (27).

Cedió Sepúlveda hemos escrito. Pero no hemos precisado lo bastante. Pues con Sepúlveda se ceden otras localidades más o menos próximas, ahora bien, siempre en la zona septentrional del que acabaría siendo el definitivo obispado segoviano, entre los de Avila y Osma y al sur del Duero..., o sea lo que pudo ser, y desde luego nosotros creemos que fue, la diócesis de Sepúlveda, de administración toledana hasta su fusión çon la de Segovia en virtud de la misma donación, una diócesis sepulvedana amputada de parte de su territorio por el sur, amputada pontificiamente a consecuencia de la creación de la diócesis de Segovia, si bien tal creación era una indirecta confirmación de la de Sepúlveda poco antes alumbrada por el no bastante mandato secular regio, amputada concretamente de la ciudad segoviana y la zona en torno a ella la cual así, habría venido a constituir su límite meridional en lugar de las tierras centrales (28).

Mas lo cierto es que, de esta manera las cosas, a los quince años escasos de su erección (29), la diócesis de Sepúlveda habia dejado definitivamente de existir. La máxima jerarquía eclesiástica de la villa seria en lo sucesivo su cabildo de clérigos, y de ahí hasta el mondo arciprestazgo de nuestros días ya posteriores al Codex juris canonici.

$Y$ llegados a este punto nos es forzoso plantearnos algunos interrogantes de causalidad. Concretamente, nada nos consta de la actitud de Sepúlveda, del poderoso concejo aforado de la villa ante la supresión de la diócesis acabada de crear. Cierto que no abundan para el lugar y las épocas las fuentes capaces de darnos información sobre cuestiones de esa índole. Pero un silencio tan total tampoco hace desde luego probable que nada especialmente significativo ocurriese. Máxime cuando algo se puede, por lo menos conjetu- 
rar, a la luz tanto de las circunstancias ambientales del momento cuanto de una cierta evolución posterior.

Ponderando todos los tales factores nosotros nos inclinamos por suponer que los sepulvedanos, por una parte, no tenían interés en ser cabeza de diócesis; y por otra preferian depender de Segovia que de Toledo.

Y es que un obispo podía ser visto como peligroso para sus novísimas libertades municipales, cual la amenaza de una cierta cuña señorial (30).

Y mientras que el obispo de Segovia, a pesar de los inconvenientes que a primera vista parecen más socorridos de la mayor proximidad, no encarnaba, por lo territorialmente compacto de su diócesis, sino la potestad canónica, al menos en principio, la subordinación al lejano Toledo podía muy bien concebirse antes que nada como la de un señorío eclesiástico de los vitandos (31).

¿Y será demasiado frívolo saltarnos de este presumible contexto a la desconfianza plasmada en el Fuero Extenso hacia los cogolludos (32)?. Pasando por el apoyo concejil a los clérigos concubinarios de la villa que resistian la justa disciplina a que el ordinario segoviano intentó someterlos, en fecha que no consta pero desde luego es ya bajomedieval (33).

¿Que todo se nos queda en hipótesis? Si al menos son capaces de despertar alguna inquietud que nos permita salir de ellas nos daríamos por conformes. Pero no sería bueno extraviarnos por su dédalo más de la cuenta y hora es ya de enfrentarnos a más de un siglo de distancia y a unas coordenadas geográficas también diversas con el paralelo conquense, para tratar así de captar lo uno y to vario en el permanente juego peninsular de fuerzas entre la reconquista y la repoblación.

\section{EL ÚLTIMO ECO DE LA EXTREMADURA CASTELLANA}

«Que toda Estremadura sea tenida de venir a Sepúlveda a fuero» se intitula el título primero del Fuero Extenso de Sepúlveda.

Un texto tardio pero que recoge la realidad histórica indubitada de toda una geopolítica que hizo en su día de Sepúlveda y su ordenamiento jurídico la cabeza de aquel país fronterizo (34) que por estar al otro lado del Duero, entre éste y el sistema central, se llamó Extremadura, aunque después, precisamente por lo acusado y esencial alli de esa misma condición fronteriza, el topónimo se hiciera sinónimo de frontera sin más y se fuera desplazando con 
la frontera hasta llegar a designar regiones del Tajo y del Guadiana, en Portugal y en España, aquí la Transierra; la Extremadura leonesa, la única Extremadura en el lenguaje de nuestros siglos XIV y XV.

Un texto tardío ése del fuero, sí, pero, insistimos, que no hace sino actualizar - y la circunstancia dicha de haber adquirido Sepúlveda la categoría de cabeza extremeña a consecuencia de la repoblación fernandina no es sino una de las pruebas de la tal actualización- los textos viejos, cual ése de la Crónica de Alfonso III, similiter et omnis extremitas que trans flumen Dorii habitatur. Y toda una transcendente evolución intermedia a propósito de la cual ha llegado a escribir Julio González (35) que «los documentos de los siglos XII y XIII consideran a la Extremadura ya poblada como una entidad distinta y parangonable a los reinos de Castilla, León o Toledo, aunque no con el título de reino".

Y entonces, y esto ya nos afecta de lleno, cuando ya la Transierra se ha apropiado del nombre de Extremadura, camino de arrebatársele a la castellana para quedarse exclusiva y permanentemente con él, aquélla, la Extremadura leonesa que ya nada comprende de la cuenca del Duero, está llamada, repetimos, a monopolizar el topónimo, pero no lo ha conseguido aún integralmente, de manera que «también se conocen como Extremadura otras tierras castellanas, especialmente los campos de Cuenca y Alcaraz». Consideración que no deja de suponer un asidero para el paralelo que sustenta este nuestro argumento.

Cuenca que, como en el caso de Sepúlveda, tiene también para los geógrafos, una situación y sobre todo una topografía predestinadas. «El contacto de la serranía con la llanura manchega es en ella el factor de situación decisivo. La hoz cavada por el Júcar era el paso natural que canalizó el movimiento de una a otra región, y para su defensa surgió la ciudad emplazada en la muela que recortan el Júcar y su afluente el Huécar, cuyas hoces forman un magnífico foso natural, haciendo de ella una inexpugnable fortaleza, en la parte opuesta al vértice de confluencia, un castillo que cierra su acceso» (36).

Y fue desde esta atalaya, nada más ganada al enemigo, desde donde el rey Alfonso VIII, consiguiendo en inmediato y prudencial plazo la venia romana, erigía la mitra conquense. Y la dotaba. 1177- 1182.

Para empezar, una analogía con Sepúlveda que puede parecer vaga, pero que deja de serlo si miramos un tanto adelante o atrás en el tiempo y un poco más allá en el espacio. 
Y es que tanto en Cuenca como en Sepúlveda nos encontramos con dos diócesis de repoblación.

Claro está que no se concebia en aquel momento histórico llenar el vacio demográfico de un territorio sin dotarle de una organización eclesiástica, sin hacerle entrar en la órbita canónica de la iglesia también territorial. Por eso el rey, a quien al fin y al cabo venía atribuido el protagonismo repoblador, fuesen luego cuales fuesen las modalidades de éste y en consecuencia su dependencia concreta del mismo, había de preocuparse de la geografía episcopal de las tierras nuevas, por la propia esencia de su suprema potestad soberana. De ahí la erección sepulvedana y la erección y dotación conquenses.

Pero una señalada diferencia ya.

Y es que Sepúlveda, aunque como diócesis desde luego, se dona a Toledo, mientras que Cuenca se concibe desde un principio cual obispado con su mitrado propio. Con tan buena ventura para el largo futuro que, hasta nuestros días ha podido decirse que, con ser tantos los haberes de la ciudad colgada en la contabilidad espiritual de la historia, es su sede prelaticia lo que más acabaría contando en el fiel de la balanza. Tal Pedro de Lorenzo, el cantor en prosa, en su «teoría de prosas de las tierras vírgenes» de Cuenca, «la Cuenca de Iberia, el relicario de Cuenca» (37).

Y retrocediendo un poco, habíamos quedado en que la repoblación de Sepúlveda empezó interesando con vistas al avance hacia Toledo hasta llegarse a la incorporación del mismo, mientras que Cuenca también ab initio interesa como un espacio en sí, proa al mediodía musulmán particularmente agresivo y afortunado entonces. $Y$ situado para colmo en una posición fronteriza con Aragón que le revestía de una trascendencia geopolítica todavía más permanente por ajena a los futuros y contingentes avatares de una reconquista cuyo fin desde luego aún no se veía. Ya hemos visto cómo Mártir Rizo podía loar sin salirse de la estricta cartografía la conquense encrucijada de todas las Iberias. Y Moxó compendia su interés repoblador al notar que «su conquista, al mismo tiempo que aseguró la ocupación de la Alcarria así como de las tierras situadas en la orilla izquierda del Tajo, impulsando el ritmo de la repoblación general del reino de Toledo por los castellanos, facilitó también el descenso de éstos desde las tierras del Júcar hacia la Mancha oriental, que se extiende a modo de gran planicie inclinada hacia Sierra Morena (38)».

Sepúlveda interesó desde siempre por Toledo. Pero como los acontecimientos se precipitaron y sólo nueve años después de esa su consumación 
repobladora que fue el fuero alfonsino - 1076 - Toledo pasaba a manos cristianas -1085 - y la frontera se corría del Duero al Tajo, dentro de la misma política territorial e incluso si queremos de prestigio pero adaptándose a las circunstancias sobrevenidas, es más, en el marco de la misma repoblación del reino de Toledo - continuidad con el futuro proceso conquense, tal y como acabamos de ver en Moxó- a pesar de estar fuera de sus límites, a la vez que pierde su importancia militar, resulta una pieza que paradójicamente se considera todavía más vinculada a la consolidación toledana, y así es entregada a la administración apostólica del primado con sede en la antigua capital visigoda. Por cierto que haciéndose esperar bastante, en 1107, dato que no podemos echar en saco roto (39).

En cambio tengamos en cuenta el delicado trance por el que la reconquista pasaba cuando se produjo el felicísimo evento de la toma de la amenazadora fortaleza de Cuenca. Toma que ha podido considerarse como uno de los momentos de exaltación bélica de la larga gesta de los ocho siglos, excepción a la plena reacción almohade contra la apoteosis cristiana de la conquista de Almería (40). Reconquista y no repoblación. Y esta capital diferencia con Sepúlveda sí que hay que tenerla omnímodamente presente.

Sin que a consecuencia de todo ese contexto Cuenca fuese a dejar de ser frontera tan pronto (41).

Y así las cosas, entra dentro del proceso natural de la sustantividad de su sede que, además de tener ésta ineludiblemente su ratio essendi en la repoblación, se convirtiese en repobladora ella misma, no sólo demográfica sino también jurisdiccionalmente, como lo ha puesto de manifiesto con algunos ejemplos convincentes José-Manuel Nieto Soria (42). Atribución por la corona a la mitra del señorío jurisdiccional que nos está denotando otra diferencia con la situación sepulvedana ya añeja. Y es la menor fuerza del concejo y en consecuencia la mayor fortaleza real, pues en Sepúlveda no se concibe, como en Cuenca ocurrió más tarde, que el rey entregara jurisdicción alguna a potestades al margen del municipio con su villa y su tierra. A cuyo propósito viene a cuento llamar la atención sobre la menor liberalidad tendente a la atracción de repobladores, que para todo el país lo acaba de advertir Lacarra: «Las tierras situadas al sur de la Sierra han perdido el carácter de salvitas que tenían las de Ultra Sierra. Pues ya no se acoge indiscriminadamente a las gentes que llegan, si bien siguen disfrutando de ciertas ventajas económicas, judiciales y militares que son recuerdo del derecho vigente en la vieja Extremadura, ahora adaptado a las nuevas circunstancias» (43). 
Una menor fuerza concejil que nosotros nos inclinamos a explicar en parte por la aparición de esas milicias permanentes que eran las Ordenes Militares, ya con su peso en el territorio conquense, que al fin y al cabo sería el punto de partída de su protagonismo en la Mancha vecina y sin solución de continuidad. Sin olvidarnos de que fue el mismo Alfonso VIII quien sólo tres años antes de la toma de Cuenca había entregado a la Orden de Santiago el castillo de Uclés que acabaría siendo la sede de la misma. Ahora bien, precisamente en la Orden de Santiago encontró el terreno más abonado y empecinado para su difusión el Fuero de Sepúlveda. Decisivo argumento de que las tornas no habían llegado en su cambio a dramatismo alguno. Que aún no se había pasado Sierra Morena...

$Y$ de esta manera se concluye nuestro excursus.

Una cala en la formación de España. Con analogías y diferencias entre dos siglos y dos territorios.

Pero desde luego un botón de muestra en la realidad de un proceso humano que no es posible negar. De esa «historia en movimiento» que para la Edad Media peninsular acaba de reivindicar José-María Lacarra (44), hija de un «estado permanente de lucha» engendrada de continuo por «la permanente oposición de Cristiandad e Islam» con el consiguiente carácter religioso de la guerra misma y «una problemática que no tiene semejanza con la europea en la repoblación del territorio reconquistado».

¿Y. qué decir de la despoblación, la otra pieza de la trilogía tejedora?. A su propósito, y como síntoma de hasta qué punto las mentes meditadoras son capaces de intuir en el pasado lo que la historiografía estricta o desdeña o no ha creido aún lo bastante maduro para incorporárselo, nos vamos a limitar a la cita de un texto tan olvidado como éste, ya viejo de casi siglo y medio, del escritor catalogado sin más como costumbrista, Serafín Estebánez Calderón (45): «La lucha de siete siglos que la diferencia de origen y el odio religioso estableció entre los árabes y los cristianos en España, y las laboriosas cuanto sangrientas progresión y superioridad que éstos fueron alcanzando sobre aquellos, establecian diversidad de fronteras entre unos y otros en el territorio español, fronteras que duraban siglos enteros. La perseverancia de los unos por conquistar y la tenacidad de los otros por defenderse, las convertían bien pronto en un desierto sangriento». 


\section{NOTAS}

(1) SAEZ, E. GIBERT, R. ALVAR, M. y GONZALEZ RUIZ-ZORRILLA, A. Los Fueros de Sepúlveda, Segovia, 1953, pp. 12 y 353-62.

(2) Aunque materialmente en copia.

(3) Fuero de Cuenca, Madrid, 1935.

(4) Véase la nota 1.

(5) MARQUES DE LOZOYA, Sepúlveda, Segovia, 1967; LINAGE CONDE, A. Hacia una biografía de la villa de Sepúlveda, Segovia, 1972, id., «En torno a la Sepúlveda de fray Justo», Homenaje a fray Justo Pérez de Urbel, O.S.B, Silos, 1976, I, pp. 575-633.

(6) Aludimos a los casos de la repoblación en tierra de nadie, pero que no dejaban de contar a la postre para el avance reconquistador que en tierra enemiga indefectiblemente seguiría. Ese fue el caso, aunque un tanto más acusadamente por lo audaz de su avanzada, de la misma repoblación de Sepúlveda.

(7) Cfr. REILLY, B.F. The kingdom of Castilla-León under queen Urraca, Princeton, 1982, p. 324.

(8) RUIZ ASENCIO, J.M. «Campañas de Almanzor contra el reino de León. 981-986", Anuario de Estudios Medievales, 5, 1968, pp. 31-64; e id., "La rebelión de Sancho Garcla, heredero del Condado de Castilla", Hispania Sacra, 22, 1969, pp. 31-67.

(9) En cuanto a la tan polémica despoblación, para esta comarca, veanse nuestros artículos: «En torno a los santos Frutos, Valentín y Engracia», Revista portuguesa de História, 27, 1978, pp. 73-104; y «Alfonso I en Sepúlveda. La mención de «Septempublica» en la «Crónica de Alfonso Ill», Asturiensia Medievalia, 3, 1979, pp. 105-38.

(10) Una constante de la geografía militar, cuya transcendencia consta desde el siglo VIII al $X X$, aunque andando el tiempo Madrid sustituyera a Toledo. Véanse para los distintos momentos históricos: SANCHEZ-ALBORNOZ, C. «ltinerario de la conquista de España por los musulmanes» Cuadernos de Historia de España, 10, 1848, p. 41; Servicio Histórico Militar. Ponente: coronel JUAN PRIEGO LOPEZ, Guerra de la Independencia. III, Madrid, 1974, pp. 135-51; y LOJENDIO, L.M. de. Operaciones militares de la guerra de España, Barcelona, 1940, pp. 54-61.

(11) Recherches sur /'histoire urbaine en León et en Castille au Moyen Age (tesis mecanografiada de la Sorbona, 1971), pp.243-8 y $438-44$ (publicado el texto sin notas ni documentos en versión española; Madrid, 1979).

(12) El mismo Gautier-Dalché nota que en los límites del alfoz de Sepúlveda, contenidos en el mismo fuero de Alfonso $\mathrm{VI}$, no se fija ninguno por el lado sur.

(13) Véase ERASO A. y otros, «Estudio del karst del cañón del Duratón», Kobie, 10, 1980, pp. 53-127. Sobre la singularidad de este paisaje, LINAGE CONDE, A. «Some pets from Spain», The Ark, 40, 1982, pp. 58-61. Y para sus distintas destinaciones en la historia, id., «Geografia religiosa y sucesión de civilizaciones en el cañón del Duratón», Bivium. Homenaje a Manuel Cecilio Díaz y Díaz, Madrid, 1983, pp. 155-66.

(14) Se ha notado lo extraño de su topografía - Camilo-José de Cela ha advertido su parecido 
con la de Cuenca- cual decisivamente inspirador de la pintura de Zuloaga; LAFUENTE FERRARI, E. La vida y el arte de Ignacio Zuloaga, seg. ed., Madrid, 1972, pp. 275-7.

(15) «Excavaciones arqueológicas antiguas y modernas en Duratón», Estudios Segovianos, separata de 1949 (sin más indicaciones), pp. 6 y 19.

(16) MOLINERO PEREZ, A. Aportaciones de las excavaciones y hallazgos casuales al Museo Arqueológico de Segovia. 1941-1959, Madrid, 1971, núm. 2661; GIL FARRES, O. «Hallazgo post-halstáttico en Segovian, // Congreso Nacional de Arqueologia. Madrid, 1951, Zaragoza, 1952, pp. 315-6 y lám. XXXIII. Una ampliación de cuanto venimos diciendo es nuestro novísimo artículo, «La dimensión militar en la historia. A propósito de la villa de Sepúlveda", Religión y Cultura, 29, 1983, pp. 453-97.

(17) Juan Ruiz ha escrito (en Calvo L. y otros, Cuenca. Cosas y gentes; Cuenca, 1977, pp. 279 y 311) que «parece probable que fueran motivos de guerra, de disputa de un definitivo asiento territorial donde hacerse fuertes, de búsqueda de un lugar idóneo para la defensa contra quienes venian empujando, el pretexto más razonable de la inversión por el hombre, porque se hace dificil pensar en el laboreo o pastoreo como estímulos ofrecidos por una geografía abrupta, rocosa, de pendientes duras y adornada por un clima nada benigno y que consecuentemente invita más que a esperar confiado a atisbar escondidon, de manera que «en Cuenca la simetría se ha ido al infinito, desafiando, cuando nadie se atrevia, la ya decrépita geometría euclidiana, y la sencillez de una quebrada ha adquirido el carácter, la quinta esencia de la proporción armónica, y se han fundado los rascacielos no para la especulación sino para el sustento, porque se ha seguido no la razón de la economía sino la simple tendencia de la plomada".

(18) Artículo así titulado, Príncipe de Viana, 27, 1966, pp. 315-9.

(19) Y hasta cierto punto comprometedor, pues suponía dejar un tanto desguarnecido el valle del Tajo, si bien hay que tener en cuenta que en septiembre del año anterior había muerto Yusuf ibn Taxufin, al otro lado del Estrecho.

(20) Además del rey y la reina Isabel, firman el infante Sancho, las infantas Teresa y Urraca y sus maridos Enrique y Raimundo, un número muy nutrido y escogido de altas dignidades seglares palatinas y territoriales; y los obispos Pedro de León, Pelagio de Astorga, Giraldo de Braga y Jerónimo de Salamanca. Sobre esa suscripción episcopal frecuentemente en las escrituras reales ha llamado la atención REILLY, B. «The court bishops of Alfonso VII of León-Castilla. 1147-1157", Mediaeval Studies, 36, 1974, pp. 67-78.

(21) El único que sepamos haya estudiado estas cuestiones, aunque sus puntos de vista no sean los nuestros, ha sido RIVERA RECIO, J.F. El arzobispo de Toledo don Bernardo de Cluny. 1086-1124, Roma, 1962 y La iglesia de Toledo en el siglo XII. 1086-1208, Roma, 1966, I, pp. 235-80y $74-9$ respectivamente y passim.

(22) Podemos aceptar como duración de ésta el periodo 1088-1108. Las fuentes son los Anales Toledanos Segundos y la Crónica latina de los reyes de Castilla. Recordemos que Sepúlveda había recibido de Alfonso VI el espaldarazo jurídico de la misma ya el año 1076. A ese propósito del cotejo comparativo de las consecuencias de la diversidad cronológica es decisivo el estudio del románico de ambas poblaciones. Lamentablemente está aun inédita la tesis de INES RUIZ MONTEJO, El románico de tierras de Segovia.

(23) No los volvemos a copiar pues ya están publicados, aunque extrañamente apenas comentados dado su interés, nos parece, para visiones históricas y jurídico-canónicas de mucho más amplio alcance. Remitimos a SANCHEZ ALBORNOZ, C. Despoblación y repoblación del valle del Duero, Buenos Aires, 1966, pp. 387-8; y RIVERA RECIO, J.F. La Iglesia, citada en la nota 21, p. 76.

(24) LINEHAN, P.A. «Segovia a "frontier" diocese in the thirteenth century", The english historical review, 106, 1981, pp. 481-508; p. 483, nota 1, uthe restored diocese of Segovia», refiriéndose expresa y concretamente a la escritura de Alfonso VI.

(25) Texto en MANSILLA, D. La documentación pontificia hasta Inocencio III. 965-1216, Roma, 1955, núm. 64; JAFFE, 6490.

(26) Sobre la tradición textual de la variante, mi libro Hacia una biografía citado en la nota 5 , notas 180-181. 
(27) Texto en COLMENARES, D. de. Historia de la insigne ciudad de Segovia y compendio de las historias de Castilla, Segovia, 1637; edición anotada de Segovia, 1969, xiv, 8.

(28) De las circunstancias motivadoras de la creación-restauradora de la diócesis segoviana, concretamente del levantamiento de los segovianos en pro de ella, prescindimos aquí. Véase España sagrada, XX, 264.

(29) Por Alfonso VI en 1107; tolerada, incluso podemos decir, insistimos, que confirmada implícitamente por Pascual II en 1122.

(30) ¿Y los de Segovia que en cambio tanto entusiasmo, hasta combativo y agresivo y violento muestran por ser obispado?. No podemos contestarnos, entre otras cosas por lo más oscuro de nuestros conocimientos sobre su régimen municipal de aquella primera hora. Aunque parece que para ellos no había otra posibilidad de librarse de Toledo. Y eso de por sí podía ser gratificante y compensatorio. Cfr, por ejemplo, LINEHAN, P.A. «The synod of Segovia. 1166», Bulletin of Medieval Canon Law, 10, 1980, pp. 31-44.

(31) ¿No serían miras ambiciosas sobre las tierras de Sepúlveda las que lievaron ya el año 1100 al arzobispo don Bernardo a consagrar en ellas la iglesia benedictina de San Frutos. Véanse: MARTIN POSTIGO, M. de la S. San Frutos del Duratón, Segovia, 1970; id., "Altonso I el Batallador y Segovia”, Estudios Segovianos, 19, 1967, pp. 205-78; LINAGE CONDE, A. "La donación por Alfonso Vl a Silos del priorato de San Frutos y el problema de la despoblación», Anuario de Historia del Derecho Español, 41, 1971, pp. 973-1011.

(32) Título 24.

(33) Archivo de la Catedral de Segovia, doc. núm. 16; apud LINEHAN, P.A. artículo citado en la nota 24, pp. 484-5: «Sancius Johannis laycus dixit quod ipse interfuit concilio ubi clerici rogaverunt concilium ut iuvarent eos contra episcopum et maior pars concilii promiserunt eis ut iuvarent illos».

(34) Naturalmente que la originalidad, la precedencia, del derecho, del Fuero de Sepúlveda, demostrada por Gibert, nos parece que decisivamente frente a la tesis de Ureña, y a la que arriba aludíamos, es un dato a tener en cuenta para esta aseveración del papel de Sepúlveda. Tal dato va siendo aceptado por la nueva historiografía. Asi Derek William Lo$\max$ (The Reconquest of Spain, Londres, 1978, p. 99) escribe que «the chief of these customary codes was the Fuero of Sepúlveda, which spread to other towns between the Duero and the Tagus. Alfonso VIII had it written down, then gave, it as a written (and therefore lees, changeable?) code to Cuenca». y Salvador de Moxó (Repoblación y sociedad en la España medieval, Madrid, 1979, pp. 238-9): “Manifestación brillante de la tarea repobladora que se iba efectuando en Cuenca y su tierra, donde la toponimia nos indica que la mayoría de sus aldeas surgen con la colaboración cristiana, así como expresión visible de la organización de su concejo, es el notable Fuero de Cuenca, el más interesante de nuestros fueros extensos, que si bien recibe su sabia de los más antiguos de Extremadura -en especial del de Sepúlveda- ofrece una técnica más avanzada y una más minuciosa precisión de situaciones propias en esta comarca de renaciente conquista, lo que justifica su expansión -como derecho local voluntariamente escogido- por la mayoría de los nucleos manchegos que se van repoblando».

(35) «La Extremadura castellana al mediar el siglo XIll», Hispania, 34, 1974, pp. 265-324 (p. 5 , nota 11).

(36) TERAN, M. de, Geografía de España y Portugal, Barcelona, 1958, IV, 1, pp. 401 y 403; apostilla que todavía en el día de hoy «Cuenca sigue fiel a su personalidad y figura de villa medieval y guerrera y conserva su bella estampa de casas encumbradas y sostenidas en un equilibrio que aparece como inestable, asomadas a las hoces de los ríos".

(37) "Emociones de salida», Obras completas, Madrid, 1974, I, p. 531.

(38) Libro citado en la nota 34, p. 237.

(39) Y por cierto, ¿qué había ocurrido hasta entonces?. ¿Cual venía siendo la situación canónica de Sepúlveda?. A nosotros no nos cabe duda de que una vez incorporada Toledo y restaurada su sede dependió de hecho de su ordinario. En cuanto a los nueve años intermedios, nos parece un plazo lo suficientemente breve como para prestarse a una situación provisoria no configurada nítidamente en el plano jurídico, y capaz de ajustarse a empíricos acomodamientos. 
(40) La revancha musulmana no se hizo esperar, en la campaña de 1182, adentraba en el rejno ya cristiano de Toledo, ante la estupefacción de poblaciones como Talavera. La excepción conquense la explica Lomax (libro citado en la nota 34, p. 116), por la paz temporal con Navarra y una epidemia en Marruecos. Otra excepción había sido la resistencia precedente de Hueta al asedio moro. El mismo Lomax destaca la valía militar de la topografía de Cuenca, «a small but prosperous city on an impugnable site». Por su parte Reilly (libro citado en la nota 7, p. 180), hace notar cómo «era la posición más avanzada que en el siglo XII amenazaba el reino de Toledo».

(41) ¿Hasta qué punto la geografía episcopal de la frontera interesaba más a los reyes por ser una garantía del mantenimiento de la religiosidad fronteriza con vistas a la misma pugnacidad vigente contra el Islam?. El problema nos desborda. En el artículo de Linehan citado en la nota 24 se discute y se aporta bibliografía -por ejemplo la tan penetrante aunque un poco alejada en el espacio y la evolución posterior de su territorio valenciano, de RobertIgnatius Burns- además de su punto de vista. Notemos, ya en la centuria siguiente, la presencia de los prelados conquenses en las conquistas de Córdoba y Sevilla por San Fernando.

(42) «El carácter feudal de las relaciones monarquía-episcopado en el ámbito castellano. El caso del obispado de Cuenca. 1180-1280», En la España medieval. III. En memoria del profesor Salvador de Moxó, Madrid, 1982, II, pp. 197-217.

(43) «Acerca de la atracción de pobladores en las ciudades fronterizas de la España cristiana; síglos XI-X||», en el volumen citado de la nota anterior, pp. 485-98. Es además imprescindible GONZALEZ, J. La repoblación de Castila la Nueva, Madrid, 1975-6, precedida del artículo del mismo "La repoblación de la Mancha", en la obra colectiva VII centenario del infante don Fernando de la Cerda. 1275-1975, Ciudad Real, 1976, pp. 1-27, separata.

(44) Artículo citado en la nota anterior, p. 485.

(45) "Toros y ejercicios de la jineta», Escenas andaluzas, (ed. B.A.E., 78, año 1955, p. 215). La primera edición es de 1846. 